\title{
PENSÃO POR MORTE NO INSS DO TRABALHADOR POLICIAL MILITAR
}

\section{DEATH IN WORKER INSS MILITARY POLICE PENSION}

\author{
Anderson Cleber Aleixo Grejanin ${ }^{1}$
}

Resumo:

Trata-se o presente Artigo do direito a pensão por morte do militar que obtêm na Justiça do Trabalho o reconhecimento do vínculo de emprego com empresa privada. Dessa forma, contribui para o regime geral de previdência social para obtenção do direito à pensão por morte conforme Artigo 201, V, da Constituição Federal e Legislação Previdenciária, art. 74 e seguintes da Lei n. 8.213/91. Dois pontos importantes, primeiro o caráter de "regime de dedicação exclusiva" que os policiais militares estão sujeitos, versus o direito constitucional ao livre exercício de qualquer trabalho ofício e ou profissão. Princípios constitucionais relevantes sobre a questão. Proteção ao trabalhador, que norteia todo o sentido da criação do Direito do Trabalho, de proteger a parte mais frágil na relação jurídica. Como o INSS e o Poder Judiciário tem enfrentado esta questão.

Palavras chave:

Policial militar, pensão por morte, vínculo empregatício, dignidade da pessoa humana.

\section{ABSTRACT:}

\footnotetext{
${ }^{1}$ Mestrando em Direito pela Faculdade Autônoma de Direito - FADISP. Bolsista CAPES. Especialista em Direito
} Constitucional pela Escola Superior de Direito Constitucional. Advogado - SP. E-mail: anderson.grejanin@ig.com.br.

http://revistasapereaude.org/index.php/edicoes/ano-5-volume-1-agosto-2016

D.O.I: 10.20523/sapereaude-ano5-vol-1-pg-25-38 
It is this Article the death pension of the military who get in the Labor Court recognition of the employment relationship with private enterprise. Thus, it contributes to the general social security scheme to obtain the right to death benefits as Article 201, V, of the Federal Constitution and Social Security Law, art. 74 and following of Law. 8.213 / 91. Two important points, the first character of "exclusive dedication" that the military police are subject versus the "fundamental principle of human dignity" and the "social function of labor" in the application of law and guarantees of fundamental rights. Comes with the labor law the principle of worker protection, which guides all towards the creation of labor law, to protect the most fragile part of the legal relationship - the worker. As the INSS and the judiciary has faced this issue.

Keywords:

Military police, death pension, employment, dignity of human person

\section{Introdução}

O benefício da pensão por morte é devido aos dependentes do segurado que falecer, aposentado ou não.

Tem direito os dependentes de qualquer segurado empregado, incluindo domésticos, avulsos, contribuinte individual, segurado especial e facultativo, todos têm direito conforme legislação vigente não existindo nenhum tipo de carência dada sua fatalidade a "morte".

http://revistasapereaude.org/index.php/edicoes/ano-5-volume-1-agosto-2016

D.O.I: $10.20523 /$ sapereaude-ano5-vol-1-pg-25-38 
A $1 \mathrm{ei}^{2}$ apenas trouxe uma limitação de tempo de recebimento do benefício da pensão por morte, caso não seja comprovado pelo cônjuge, contribuição mínima de 18 meses e pelo menos 24 meses de casamento e ou união estável, além de excluir o caráter vitalício da pensão, não sendo mais possível para cônjuges jovens, ou seja, pessoas com expectativa de vida, hoje, acima de 35 anos.

Os pressupostos para sua concessão é o óbito do segurado; qualidade de segurado do falecido e qualidade de dependente do beneficiário (falecido).

A renda mensal da pensão será $50 \%$ do salário mais $10 \%$ por dependente até o limite de $100 \%$ com exceção para órfãos de pai e mãe.

\section{Conceito}

O benefício de pensão por morte está previsto no artigo 201 , V, da Constituição Federal, com a redação dada pela Emenda Constitucional n. 20/98, in verbis:

“Art. 201. A previdência social será organizada sob a forma de regime geral, de caráter contributivo e de filiação obrigatória, observados critérios que preservem o equilíbrio financeiro e atuarial, e atenderá, nos termos da lei, a:

\section{(...)}

V - pensão por morte do segurado, homem ou mulher, ao cônjuge ou

\footnotetext{
${ }^{2}$ Alínea b, inciso V do Art. 77 da Lei no 13.14615, que alterou a Lei no 8.21391.
} 
companheiro e dependentes, observado o disposto no $\S 2^{\circ 3}$.

Dessa forma, cabe à lei vigente por ocasião do óbito estabelecer os requisitos necessários para a concessão da prestação previdenciária.

De acordo com art. 74 e seguintes da Lei n. $8.213 / 91^{4}$, essa proteção social é devida aos dependentes do segurado que falecer e independe de carência. Corresponde a 100 (cem) por cento do valor da aposentadoria que o segurado recebia ou a que teria direito se estivesse aposentado por invalidez na data de seu falecimento.

De outro modo, "Não é devida pensão por morte quando na data do óbito tenha ocorrido a perda da qualidade de segurado, salvo se o falecido havia implementado os requisitos para a obtenção de aposentadoria, ou se por meio de parecer médico-pericial ficar reconhecida a existência de incapacidade permanente do falecido, dentro do período de graça" ${ }^{5}$.

\section{Do reconhecimento do vínculo de emprego}

No caso, muitos policiais militares com o objetivo de aumento da renda familiar, buscam um novo emprego.

\footnotetext{
${ }^{3}$ Art. 201, V, da Constituição Federal de 1988. http://www.planalto.gov.br/ccivil_03/Constituicao/Constituicao.htm

${ }^{4}$ Art. 74, da Lei 8.21391, http://www.planalto.gov.br/ccivil_03/leis/L8213cons.htm

${ }^{5}$ consoante elucidam Carlos Alberto Pereira de Castro e João Batista Lazzari (in Manual de Direito Previdenciário. $15^{\mathrm{a}}$ ed. Rio de Janeiro: Forense, 2013, p. 791).
}

http://revistasapereaude.org/index.php/edicoes/ano-5-volume-1-agosto-2016

D.O.I: 10.20523/sapereaude-ano5-vol-1-pg-25-38 
A legislação trabalhista é clara ao dizer em seu Artigo 29, da CLT, que os empregadores terão o prazo de 48 (quarenta e oito) horas para fazer as anotações nas Carteiras de Trabalho de seu empregado ${ }^{6}$, sem exceção.

O descumprimento do Artigo acima, dá direito ao trabalhador o acesso à justiça especializada do trabalho para haver reconhecido seu direito.

A questão da possibilidade ou não do policial militar ter outro emprego já não há mais dúvida, foi solucionada pela Justiça Especializada do Trabalho na Súmula $\mathrm{n}^{\circ} 386$ do TST.

\section{Súmula no 386 do TST}

POLICIAL MILITAR. RECONHECIMENTO DE VÍNCULO EMPREGATÍCIO COM EMPRESA PRIVADA (conversão da Orientação Jurisprudencial no 167 da SBDI-1) - Res. 129/2005, DJ 20, 22 e 25.04 .2005

Preenchidos os requisitos do art. $3^{\circ}$ da CLT, é legítimo o reconhecimento de relação de emprego entre policial militar e empresa privada, independentemente do eventual cabimento de

\footnotetext{
6 Brasil, Decreto Lei $n^{\circ}$ 5.452, de $1^{\text {o }}$ de maio de 1943, Consolidação das leis do Trabalho. http://www.planalto.gov.br/ccivil_03/decreto-lei/Del5452.htm
} 
penalidade disciplinar prevista no Estatuto do Policial Militar. (ex-OJ no 167 da SBDI-1 - inserida em 26.03.1999) ${ }^{7}$.

Precedentes:

EEDRR 229887/1995 - $\quad$ Min. Leonaldo Silva

DJ 03.04.1998 - $\quad$ Decisão $\quad$ unânime

ERR 183025/1995, Ac. 5124/1997 - Min. Milton de Moura França DJ 14.11.1997 - - Decisão unânime ERR 156012/1995, Ac. 2526/1997 - Min. Ronaldo Lopes Leal DJ 27.06.1997 - - Decisão unânime ERR 82932/1993, Ac. 0038/1996 - Min. Cnéa Moreira DJ 23.08.1996 - Decisão unânime

Diferente do que ocorre no Direito Comum, onde se busca a igualdade das partes, no direito do trabalho é notória essa desigualdade econômica, fazendo com que o legislador e o julgador se veja obrigado a pelo menos tentar igualar essa diferenciação.

Esta diferença entre as partes se dá especialmente porque o empregador possui o poder de dirigir o empregado. Não poderia o direito tratar igualmente aqueles que flagrantemente são desiguais.

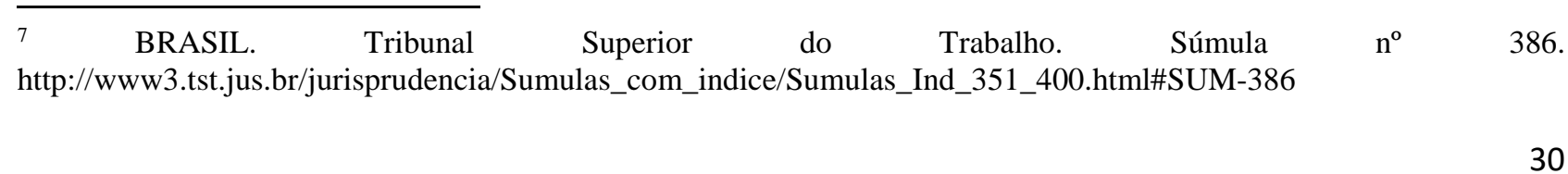

http://revistasapereaude.org/index.php/edicoes/ano-5-volume-1-agosto-2016

D.O.I: 10.20523/sapereaude-ano5-vol-1-pg-25-38 


$$
\text { O trabalhador carrega consigo uma história de escravidão, }
$$

considerado coisa, por isso só basta para tentar justificar os princípios norteadores do direito do trabalho ${ }^{8}$.

\section{Da condição de dependente}

No que concerne à condição de dependente, o art. 16 da Lei n. 8.213/91 ${ }^{9}$ enumera as pessoas assim consideradas, cuja caracterização pressupõe relação de dependência econômica com o segurado, haja vista que o benefício corresponde à renda que ele proporcionaria caso não fosse atingido pela contingência social.

Em outras palavras, essa qualificação decorre de um vínculo jurídico e de um vínculo econômico. Na espécie, tal situação deverá ser demonstrada com documentos, seja certidão de casamento e ou de união estável, para evidenciar que o polo ativo é ocupado pelo cônjuge do falecido.

\section{Da condição de Segurado}

No que tange à condição de segurado do instituidor da pensão, ou seja, “o falecido", é segurado da Previdência Social, pessoa física que exerce atividade vinculada ao RGPS ou recolhe contribuições previdenciárias.

\footnotetext{
${ }^{8}$ MARTINS, Sergio Pinto. Fundamentos de direito do trabalho. 14. Ed. Atlas: São Paulo, 2013.

${ }^{9}$ Art. 16 da Lei 8.21391, http://www.planalto.gov.br/ccivil_03/leis/L8213cons.htm
}

http://revistasapereaude.org/index.php/edicoes/ano-5-volume-1-agosto-2016

D.O.I: $10.20523 /$ sapereaude-ano5-vol-1-pg-25-38 
Impende tecer algumas considerações a respeito da manutenção desta qualidade no denominado período de graça.

O período de graça é o interstício no qual é mantida a proteção previdenciária após o encerramento do exercício de atividade remunerada ou a interrupção das contribuições. Esta é a disciplina estatuída pelo art. 15 da Lei n. 8.213/91, que em princípio, a manutenção da qualidade de segurado perdura por um período de 12 (doze) meses, o qual pode ser prorrogado por até 24 meses se houver o pagamento de mais de 120 contribuições mensais sem interrupção que acarrete a perda desta qualidade $\left(\S 1^{\circ}\right)$. A este prazo ainda pode ser acrescentado mais 12 (doze) meses no caso de desemprego $\left(\S 2^{\circ}\right)^{10}$.

$\mathrm{Na}$ hipótese da sugestão do Artigo analisamos um vínculo empregatício reconhecido pela Justiça do Trabalho.

O INSS não pode se recusar a receber contribuições previdenciárias alegando que, pelo fato do "de cujus" ser policial militar, portanto possuindo vinculo estatutário com o Estado de São Paulo, alegando ser incompatível a com a atividade de segurança que teria exercido junto a empresa privada.

Ora, o regime de previdência é de caráter contributivo, portanto sem discriminação, e ou impedimentos, já que houve reconhecimento de vínculo empregatício por sentença judicial e contribuição à Previdência Social.

A acumulação da qualidade de segurado de Regime Próprio da Previdência dos militares do Governo do Estado de São Paulo com a qualidade de segurado do

\footnotetext{
${ }^{10}$ Art. 15 da Lei 8.21391, http://www.planalto.gov.br/ccivil_03/leis/L8213cons.htm
} 
Regime Geral de Previdência Social, é permitida desde que haja contribuições para cada um dos regimes e também não haja nenhuma averbação de um regime sobre o outro.

\section{Do regime de dedicação exclusiva}

De fato, a Lei Complementar n. 893 do Estado de São Paulo, de 09/03/2001, ao instituir o Regulamento Disciplinar da Polícia Militar, estabelece expressamente no seu artigo $8^{\circ}, \S 1^{\circ}$ que: "Ao militar do Estado em serviço ativo é vedado exercer atividade de segurança particular, comércio ou tomar parte da administração ou gerência de sociedade comercial ou dela ser sócio ou participar, exceto como acionista, cotista ou comanditário"11.

Portanto, entendo que tal preceito é de regime administrativo, sem força contra a legislação ordinária federal que institui o regime contributivo previdenciário.

Perfeitamente possível o reconhecimento da qualidade de segurado perante o Regime Geral de Previdência, independente de acumular o exercício da atividade de Policial Militar no Governo do Estado de São Paulo com a de segurança particular/vigilante.

A constituição Federal em seu Artigo $5^{\circ}$, dos direitos e garantias fundamentais, diz ser livre o exercício de qualquer trabalho, ofício ou profissão, atendidas as qualificações profissionais que a lei estabelecer ${ }^{12}$.

11 Estado de São Paulo. Lei complementar 893 de 09 de março de 2001. http://www.al.sp.gov.br/repositorio/legislacao/lei.complementar/2001/lei.complementar-893-09.03.2001.html

${ }^{12}$ Inciso XIII, da Constituição Federal de 1988. http://www.planalto.gov.br/ccivil_03/Constituicao/Constituicao.htm

http://revistasapereaude.org/index.php/edicoes/ano-5-volume-1-agosto-2016

D.O.I: $10.20523 /$ sapereaude-ano5-vol-1-pg-25-38 


\section{Princípios Constitucionais e Trabalhistas}

Os princípios são asserções colocadas pela ciência que nos informa e orienta na falta de disposições legais ${ }^{13}$.

São proposições que indicam somente a direção em que está situada a regra a ser encontrada, como que determinando um primeiro passo direcionador de outros passos para a obtenção do resultado ${ }^{14}$.

A dignidade da pessoa humana, regra matriz dos direitos fundamentais, que pode ser definido como núcleo fundamental do constitucionalismo moderno ${ }^{15}$ é capaz de orientar a solução desse tema.

Aliás, sobre direitos fundamentais o STF já se pronunciou que eles não se restringem apenas ao Artigo $5^{\circ}$ da $\mathrm{CF}$, podendo ser encontrado ao longo do texto constitucional $^{16}$.

O direito social ao trabalho, instrumento essencial para assegurar a todos uma existência digna, a valorização do trabalho humano conforme estabelecido no Art. 170 da CF, são instrumentos essenciais da ordem econômica.

\footnotetext{
${ }^{13}$ MARTINS, Sergio Pinto. Fundamentos de direito do trabalho. 14. Ed. Atlas: São Paulo, 2013.

${ }^{14}$ AVILA, Humberto. Teoria dos princípios. 16 ${ }^{\text {a }}$ Ed. Malheiros Editores: São Paulo, 2015.

${ }^{15}$ SILVA, José Afonso da. Curso de direito constitucional positivo. 34. Ed Malheiros Editores: São Paulo, 2012.

${ }^{16}$ O relator Ministro Sydney Sanches - medida cautelar, RTJ 150/68 - no julgamento da ADI 939-7DF, entendeu tratarse de clausula pétrea a garantia constitucional prevista no art. 150, III, "b", declarando que a EC n.3.93, ao pretender subtraí-la da esfera dos destinatários da norma, estaria ferindo o limite material previsto no art. $60, \S 4^{\circ}, \mathrm{IV}$, da CF/88.
}

http://revistasapereaude.org/index.php/edicoes/ano-5-volume-1-agosto-2016

D.O.I: $10.20523 /$ sapereaude-ano5-vol-1-pg-25-38 
O princípio da proteção ao trabalho visa compensar uma superioridade econômica do empregador em relação ao empregado, conferindo superioridade jurídica.

$\mathrm{Na}$ dúvida interpreta-se em favor do operário, in dubio pro operário, não adianta rotular o empregado de autônomo, chamar seu trabalho de bico e ou tentar enquadrá-lo como eventual, pois valerá a situação realmente existente entre as partes em face do princípio da realidade ${ }^{17}$.

\section{Conclusão: Como o Poder Judiciário e o INSS tem enfrentado essa questão}

O INSS não reconhece o vínculo empregatício reconhecido em Reclamação Trabalhista, não averba esse tempo para fins previdenciários, seja aposentadoria ou pensão.

Existe uma grande contradição no ordenamento jurídico brasileiro em relação aos efeitos da Sentença Trabalhista que reconhece uma relação de emprego, isso porque a Justiça do Trabalho, mais próxima dos direitos sociais, é capacitada para entender corretamente as necessidades dos trabalhadores, quanto o órgão previdenciário brasileiro age como incapacitados para gerir eficazmente todos os anseios sociais.

A Sentença Trabalhista, além de todos os seus efeitos, também serve para a União cobrar as contribuições sociais caso o empregador não faça o recolhimento que fora determinado pela Justiça.

${ }^{17}$ MARTINS, Sergio Pinto. Fundamentos de direito do trabalho. 14. Ed. Atlas: São Paulo, 2013.

http://revistasapereaude.org/index.php/edicoes/ano-5-volume-1-agosto-2016

D.O.I: $10.20523 /$ sapereaude-ano5-vol-1-pg-25-38 
A União tem o dever e a obrigação de cobrança das contribuições Fiscais, tributárias e acessórias das empresas.

A grande contradição é que a o Estado brasileiro, através da jurisdição trabalhista, profere uma Sentença, onde reconhece direitos aos trabalhadores e o INSS usa contra, como meio de defesa, o fato de não ter sido parte na reclamatória trabalhista, portanto não pode ser atingido pela coisa julgada e também argumenta que o Art. 55, $\S 3^{\circ}$ da Lei 8.213/91 determinada que o reconhecimento de tempo de serviço para fins previdenciários só será aceito quando realizado início de prova material, não sendo admitida prova exclusivamente testemunhal ${ }^{18}$.

As fundamentações do INSS não são sustentáveis no atual ordenamento jurídico vigente, o trabalhador não pode ser prejudicado pela negligencia do Poder Público em exercer a fiscalização e regularização das contribuições previdenciárias.

O STJ, já enfrentou essa questão e já existe jurisprudência que entende que a sentença trabalhista supre e ou serve de início de prova material para reconhecimento de tempo de contribuição do trabalhador, e a título de exemplo podemos citar o Recurso Especial 147.454/DF ao qual reconheceu a sentença trabalhista como prova material para fins previdenciários ${ }^{19}$.

Portanto diante de tudo que foi exposto no presente artigo, das dificuldades do trabalhador teve de buscar seu reconhecimento do vínculo de emprego na justiça,

\footnotetext{
${ }^{18}$ Art. 55, § 3º da Lei 8.21391, http://www.planalto.gov.br/ccivil_03/leis/L8213cons.htm

${ }^{19}$ BRASIL, Superior Tribunal de Justiça. AgRg no Agravo Em Recurso Especial no 147.454-DF (2012/0040868-3).

https://ww2.stj.jus.br/processo/revista/documento/mediado/?componente=ITA\&sequencial=114462 $2 \&$ num_registro $=201200408683 \&$ data $=20120515 \&$ formato $=P D F$
}

http://revistasapereaude.org/index.php/edicoes/ano-5-volume-1-agosto-2016

D.O.I: 10.20523/sapereaude-ano5-vol-1-pg-25-38 
das garantias e dos princípios constitucionais e trabalhistas, da falta de reconhecimento do INSS em aceitar uma decisão proferida pelo próprio Estado, concluímos que o INSS tem o dever e a obrigação em aceitar decisão judicial para incluir o tempo de serviço do trabalhador para fins previdenciários.

\section{BIBLIOGRAFIA:}

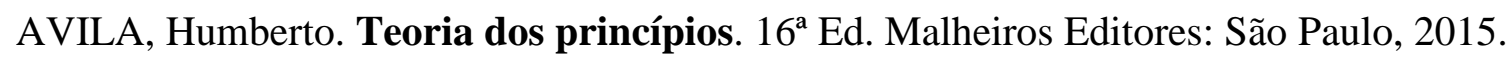

BARroso, Luís Roberto. A Dignidade da Pessoa Humana no Direito Constitucional Contemporâneo. A Construção de um Conceito Jurídico à luz da Jurisprudência Mundial. Belo Horizonte. Ed. Fórum. 2013.

BRASIL, Decreto Lei $\mathbf{n}^{\mathbf{0}} \mathbf{5 . 4 5 2}$, de $1^{\circ}$ de maio de 1943, Consolidação das leis do Trabalho. http://www.planalto.gov.br/ccivil_03/decreto-lei/Del5452.htm

BRASIL, Lei $\mathbf{n}^{\mathbf{0}} \mathbf{8 . 2 1 3}$, de 24 de julho de 1991 . http://www.planalto.gov.br/ccivil_03/leis/L8213cons.htm

BRASIL, Lei $\mathbf{n}^{\mathbf{0}} \mathbf{1 3 . 1 0 5} / \mathbf{2 0 1 5}$, de 17 de Junho de 2015. Disponível em: http://www.planalto.gov.br/ccivil_03/_Ato2015-2018/2015/Lei/L13135.htm. Acesso em: 21.07.16.

http://revistasapereaude.org/index.php/edicoes/ano-5-volume-1-agosto-2016

D.O.I: 10.20523/sapereaude-ano5-vol-1-pg-25-38 
BRASIL, Lei $\mathbf{n}^{\mathbf{0}}$ 13.146/2015, de 06 de julho de 2015. Disponível em: http://www.planalto.gov.br/ccivil_03/_Ato2015-2018/2015/Lei/L13146.htm\#art101. Acesso em 21.07.16.

BRASIL, Superior Tribunal de Justiça. AgRg no Agravo Em Recurso Especial no 147.454-DF (2012/0040868-3).

https://ww2.stj.jus.br/processo/revista/documento/mediado/?componente=ITA\&sequencial=114462 2\&num_registro $=201200408683 \&$ data $=20120515 \&$ formato $=P D F$

CASTRO, Carlos Alberto Pereira de. LAZZARI, João Batista. Manual de Direito Previdenciário. $15^{\mathrm{a}}$ ed. Rio de Janeiro: Forense, 2013.

EDUARDO, Ítalo Romano. EDUARDO, Jeane Tavares Aragão. Curso de direito previdenciário. 10a. Ed. Elsevier, 2013.

MARTINS, Sergio Pinto. Fundamentos de direito do trabalho. 14. Ed. Atlas: São Paulo, 2013.

SILVA, José Afonso da. Curso de direito constitucional positivo. 34. Ed Malheiros Editores: São Paulo, 2012. 